\title{
Abandonment of Family Planning among Women in Period of Genital Activity in the City of Mahajanga Madagascar
}

\author{
Ratsiambakaina D, MD, MPH*, Rakotomalala MFJ, Fidison F, Rakotonirina ELC and Randaoharison PG \\ Faculty of Medicine, University of Mahajanga, Madagascar
}

${ }^{\star}$ Corresponding author: Ratsiambakaina D, MD, MPH, Faculty of Medicine, University of Mahajanga, Madagascar

Received: June 24, 2021; Accepted: July 08, 2021; Published: July 16, 2021

\section{Introduction}

The World Health Organization or WHO defines family planning as the set of measures to promote births, act on the interval between births, prevent unwanted births and give each couple the means of determining the number of children he wants [1].

Poor access to family planning is associated with unintended pregnancies and poorer maternal and newborn outcomes, including abortion-related morbidity and mortality [2]. Unmet need for contraception refers to the percentage of sexually active and fertile women who either no longer want children or are delaying the next child, but are not using contraception. Meeting unmet need helps increase contraceptive use and reduce unintended pregnancies, which improves health outcomes and offers great social and economic benefits to women, their families, and society [3].

According to the $\mathrm{WHO}$, in developing countries that wish to delay having a child or stop having children but do not use any contraception, the number of women is estimated at 225 million [4].

Family planning therefore appears as one of the solutions likely to allow socio-economic development to gain some ground in relation to population growth [5].

Madagascar faces many demographic and health challenges which have negative consequences on economic emancipation. The country has a young population, two-thirds of which are under the age of 25 [6]. The first step in the process of accelerating economic growth is based on declining fertility [7]. Note that the national fertility index was 4.9 in 2018 [8].

According to the 2012-2018 annual report, the modern contraceptive coverage rate has increased considerably, from $27.8 \%$ in 2012 to $34.6 \%$ in 2018. On the other hand, the unmet need for contraceptive methods has decreased by $28 \%$. in 2012 to $24.9 \%$ in 2018 [9].

Increasing access to family planning and meeting unmet need for contraception are key goals for improving reproductive health. Madagascar is committed to the Global Family Planning 2020 partnership to improve access to family planning [6].

Thus, stopping contraceptives has significant repercussions, not only for family planning and maternal and child health, but also for population growth and the overall economic development of countries. Most women who stop using contraceptives do so at the start of their contraceptive use and without consulting a health care professional [10].

A study on family planning dropouts seemed necessary to us in Mahajanga, in order to identify the causes of women abandoning contraception.

\section{Methodology}

We carried out this study in the city of Mahajanga, among women in genital activity. This is a 3-month observational, descriptive and cross-sectional study, running from August 1 to October 31, 2019.

We included in this study all women aged 15 to 49 who had agreed to participate in the survey and had temporarily or permanently abandoned the contraceptive method.

The parameters evaluated were the variables related to the sociodemographic profiles of the women, to the data concerning the knowledge of these women in matters of family planning and the causes of discontinuation or abandonment.

\section{Results and Discussion}

Among these women who had abandoned modern contraceptive methods, $33.46 \%$ had used pills, $31.91 \%$ injectables and $27.63 \%$ condoms. In the other studies as well, users of pills and injectable contraceptives were the most frequent users of family planning, but in different proportions $[11,12]$.

It was a temporary abandonment in $95.33 \%$ of cases, final in $4.67 \%$. Several reasons were mentioned by the women, but the most important were the desire for a child, the opposition of the husband or partner, side effects, rumors and contraceptive failure. Thus, the desire for a child was the first motive pushing women to abandon modern contraception, found in $31.5 \%$ of cases.

This result was comparable to those of other studies which found that stopping the use of contraceptive methods was mainly due to a desire to have a child [13-15].

This would explain the relatively small number of children in our study, which witnessed not reaching the desired number of 
Ratsiambakaina D, Rakotomalala MFJ, Fidison F, Rakotonirina ELC, Randaoharison PG (2021) Abandonment of Family Planning among Women in Period of Genital Activity in the City of Mahajanga Madagascar.

children. Partner opposition was the second reason for stopping the contraceptive method, found in $27.20 \%$ of cases, as reported in other studies $[16,17]$.

The problem of family planning is a couple's affair and the role of the partner must be preponderant before and after the choice of the contraceptive method. Yet, according to some authors, the majority of men believe that they have the absolute right, the power to decide on the use of modern contraception by their wives $[16,17]$.

The problem of side effects was the third reason for giving up contraception, with $10.5 \%$ of cases. These side effects are multiple and depend on the contraceptive method used. Thus, each user must be informed at the time of the choice $[18,19]$.

Negative rumors, mentioned by $10.1 \%$ of women, represent a phenomenon that compromises the development of modern contraceptive use. According to these rumors, modern contraceptives are the cause of serious disease such as cervical cancer or breast cancer, and are the cause of secondary infertility.

Thus, these rumors cause concern among users and may lead them to quit permanently, bringing back to the question of the sufficiency of information on family planning $[20,21]$.

Among the women surveyed who temporarily gave up family planning, the majority resumed contraception using the same contraceptive method as before. Thus, the female family planning users in this study were almost faithful to the latest methods they used, despite the various reasons for quitting.

In addition, they were easy to convince about the use of family planning in the future, while the remaining $12 \%$, those who encountered difficulties, said they did not intend to use it in the future.

\section{Conclusion}

The study on the reasons for abandoning the contraceptive method of women of childbearing age carried out in the city of Mahajanga has provided interesting information.

The results of this study showed that the majority of women surveyed were already aware of the existence of different contraceptive methods, and they were in favor of the use of modern contraception.

Among contraceptive methods, pills rank first, followed by injectable methods and condoms. The majority of these women are under 30, married or single, self-employed, with more than one living child, with at least secondary education. In almost $90 \%$ of cases, they gave up contraception temporarily for different reasons. For example, the desire for a child, lack of information, fear of opposition from a family member, and side effects were cited as reasons for giving up or not using contraceptive methods. Therefore, any effort to increase contraceptive prevalence should target these factors to optimize achievement of this goal.

\section{Keywords: Abandonment, Family planning, Woman, Mahajanga}

\section{References}

1. Gentilini M (1988) Tropical Medicine. Paris: Flammarion.

2. Ahmed S, Li Q, Liu L, Tsui AO (2012) Maternal Deaths Alerted by Contraceptive Use: An Analysis of 172 Countries. Lancet 380: 111-125. [crossref]

3. Andrzej K (2018) Overcoming the Challenges of Family Planning in Africa: Towards Meeting Unmet Needs and Increasing Service Delivery; African Journal of Reproduction Health 22: 14-15. [crossref]

4. WHO. Family planning. WHO 2016 May [Accessed 07/07/2019]. Available at the URL http://www.who.int/topics/family_planning/fr/

5. Alkema L, Chou D, Hogan D, Zhang S, Moller AB, et al. (2015) Global, regional, and national levels and trends in maternal mortality between 1990 and 2015, with scenario-based projections to 2030: a systematic analysis by the UN Maternal Mortality Estimation Inter-Agency Group. Lancet 387 : 462-474. [crossref]

6. Ministry of Public Health. National budgeted action plan for family planning in Madagascar 2016-2020: MSP.2016; 9-21.

7. UNFPA Madagascar. National Conference on Family Planning: Demographic Dividend. September 14, 2016

8. INSTAT. Multiple Indicator Cluster Surveys. Fertility and Family Planning: INSTAT .MICS.Madagascar.2018

9. Track20. Summary of Main Indicators: FP2020 Annual Report 2018-2019. Madagascar. 2019

10. Castle S and Askez I (2015) Stopping Contraceptives: Reasons, Challenges, Solution. Preliminary Report. Population Council 47.

11. Track20. Summary of Key Indicators: FP2020 Annual Report 2018-2019. Ethiopia 2019.

12. Track20. Summary of Key Indicators: FP2020 Annual Report 2018-2019. Rwanda. 2019

13. Andriamialisoa (2007) Epidemiological profile of those lost to follow-up family planning at the CSB2 of Moramanga: Thesis in Med Tana 47.

14. Mahamadou S (2019) Use of Family Planning services in the health area of the rural commune of Farako of the health district of Ségou from January 1 to December 31, 2018: Thesis in Med. BAMAKO. 45.

15. Ravonisoa (2006) Family Planning: The reasons for the low use in Analavory, Manakara in 2006: Thesis in Med Tana. $\mathrm{N}^{\circ} 7530.44$.

16. Mahougnon AT (2019) Choice and effectiveness of contraceptive methods: reduction in unmet need for family planning. International Review of Marketing and Strategic Management 1: 23-42.

17. Vouking MZ, Evina CD, Tadenfok CN (2014) Male involvement in family planning decision making in sub-Saharan Africa-what the evidence suggests. The Pan African Medical Journal 7: 19-33. [crossref]

18. PSI Madagascar (2003) Study on the knowledge, attitudes and practices of young people aged 15 to 24 in Toamasina in terms of family planning. PSI / Mad. 2003: 6-9.

19. Vololoniaina N (2007) Prevalence of side effects of modern contraceptives to CSB2 of Amparafaravola. Antananarivo: Medicine thesis $n^{\circ}$ 5812: 27-30.

20. Razafimiarantsoa TT (2004) Exposure to the risk of pregnancy. EDS 97-107.

21. PSI Madagascar (2006) Family planning training. Antananarivo: Institute of Educational Technology and Management 14-15.

\section{Citation:}

Ratsiambakaina D, Rakotomalala MFJ, Fidison F, Rakotonirina ELC, Randaoharison PG (2021) Abandonment of Family Planning among Women in Period of Genital Activity in the City of Mahajanga Madagascar. ARCH Women Health Care Volume 4(4): 1-2. 